\title{
In vitro free radical scavenging capacity of thyroid hormones and structural analogues
}

\author{
L Oziol $^{1}$, P Faure ${ }^{1}$, C Vergely ${ }^{3}$, L Rochette ${ }^{3}$, Y Artur ${ }^{1}$ \\ and $\mathbf{P}$ Chomard $^{1,2}$ \\ 'Unité de Biochimie, Pharmacologie et Toxicologie, UFR des Sciences Pharmaceutiques et Biologiques, 7, Boulevard Jeanne d'Arc, BP 87900, \\ 21079 Dijon Cedex, France \\ ${ }^{2}$ Laboratoire de Biochimie Clinique, Département Génie Biologique, IUT de Dijon, Boulevard Docteur Petitjean, BP 17867, 21078 Dijon Cedex, France \\ ${ }^{3}$ Laboratoire de Physiopathologie et Pharmacologie Cardiovasculaires Expérimentales, Facultés de Médecine et de Pharmacie, 7, Boulevard Jeanne d'Arc, \\ BP 87900, 21079 Dijon Cedex, France \\ (Requests for offprints should be addressed to P Chomard; Email: pchomard@u-bourgogne.fr)
}

\begin{abstract}
It was reported that thyroid hormones decreased $\mathrm{Cu}^{2+}{ }_{-}$ induced low-density lipoprotein (LDL) oxidation in vitro. Here, we investigated free radical scavenging capacities of thyroid hormones (3,5,3'-tri-iodo-L-thyronine $\left(\mathrm{T}_{3}\right)$, thryoxine $\left(\mathrm{T}_{4}\right)$ and $3,3^{\prime}, 5^{\prime}$-tri-iodo-L-thyronine $\left.\left(\mathrm{rT}_{3}\right)\right)$ and structural analogues (L-thryonine $\left(\mathrm{T}_{0}\right), 3,5,3^{\prime}-$ tri-iodothyroacetic acid $\left(\mathrm{TA}_{3}\right)$ and 3,5,3',5'-tetraiodothyroacetic acid $\left(\mathrm{TA}_{4}\right)$ ), using three different models of free radical generation. $\mathrm{T}_{0}, \mathrm{~T}_{3}$ and $\mathrm{TA}_{3}$ slowed down production of conjugated diene and thiobarbituric acidreactive substances during LDL oxidation by $2,2^{\prime}$-azobis[2-amidinopropane] (water-soluble), whereas $\mathrm{rT}_{3}, \mathrm{~T}_{4}$ and $\mathrm{TA}_{4}$ had practically no effect. In this system, $\mathrm{T}_{0}$ was the more active compound. Using a 1,1-diphenyl-2picrylhydrazyl (lipid-soluble) test, all compounds also
\end{abstract}

revealed free radical scavenging capacities, but $\mathrm{rT}_{3}, \mathrm{~T}_{4}$ and $\mathrm{TA}_{4}$ were more active than $\mathrm{T}_{0}, \mathrm{~T}_{3}$ and $\mathrm{TA}_{3}$. $\mathrm{T}_{3}$ was able to scavenge superoxide anion and hydroxyl radicals generated in an aqueous phase by a xanthine-xanthine oxidase system, as measured by electron paramagnetic resonance spectroscopy. It may be concluded that: (1) thyroid hormones and analogues with a $4^{\prime}$-hydroxy diphenylether structure have free radical scavenging capacities, (2) this property is influenced by the number of iodines on the phenolic ring, and (3) thyroid hormone scavenging capacity should not be the only mechanism explaining their protective effect on $\mathrm{Cu}^{2+}$-induced LDL oxidation. The physiological significance of the findings is discussed.

Journal of Endocrinology (2001) 170, 197-206

\section{Introduction}

It is well-known that thyroid hormones play a role in lipid metabolism. Hypothyroidism is associated with hypercholesterolemia and increased plasma low-density lipoprotein (LDL) concentrations, which are reversed by thyroid hormone treatment (O'Brien et al. 1997). In contrast, hyperthyroidism leads to low total and LDL cholesterol concentrations, which are normalized by radioactive iodine treatment (Kung et al. 1995). Increased LDL cholesterol is a major risk factor for atherosclerosis and many data support a proatherogenic role for oxidized LDL (Steinberg 1997). Thus the lipid metabolism perturbations observed during hypothyroidism increase atherogenic risk whereas treatment of hypothyroid patients with thyroid hormone reduces it (Martinez Triguero et al. 1998). As the oxidizability of LDL was reported to be increased in hypothyroidism (Diekmann et al. 1998), it may also contribute to induce the atherogenic process.
The in vitro demonstration that thyroid hormones limit the oxidative modifications of LDL was first reported by Hanna et al. (1993). They found that thyroxine $\left(\mathrm{T}_{4}\right), 3,5,3^{\prime}$-tri-iodothyronine $\left(\mathrm{T}_{3}\right)$ and $3,3^{\prime}, 5^{\prime}$ tri-iodothyronine $\left(\mathrm{rT}_{3}\right)$ similarly decreased $\mathrm{Cu}^{2+}$-induced LDL oxidation. Using the same pro-oxidant system, we previously showed that not only thyroid hormones, but also their acetic derivatives and thyronines lacking iodine, had LDL-antioxidant properties (Chomard et al. 1998). More precisely, our data suggested that the antioxidant efficiency was related to the 4'-hydroxydiphenylether structure and depended upon the nature and the position of substituents in this structure. However, the mechanism by which these compounds act is at present not elucidated.

Antioxidants that protect lipid LDL from peroxidation may act in different ways, including sparing of endogenous antioxidant vitamins within the LDL particle, metal chelating activity or free radical scavenging. The aim of the present study was to investigate the in vitro free radical 
scavenging capacities of thyroid hormones and structural analogues: iodotyrosine, precursor of thyroid hormones (monoiodotyrosine (MIT)); thyronines (L-thyronine $\left(\mathrm{T}_{0}\right.$, no iodine), $\mathrm{T}_{3}, \mathrm{rT}_{3}$ and $\mathrm{T}_{4}$ ); and acetic catabolites of thyroid hormones (3,5,3'-tri-iodothyroacetic acid $\left(\mathrm{TA}_{3}\right)$ and $3,5,3^{\prime}, 5^{\prime}$-tetra-iodothyroacetic acid $\left.\left(\mathrm{TA}_{4}\right)\right)$. Butylated hydroxytoluene (BHT), a common phenolic antioxidant, was used as antioxidant control.

Experiments were performed using three different models of free radical generation. In one experiment, LDL oxidation was initiated by the water-soluble azoinitiator, 2,2'-azobis-[2-amidinopropane] dihydrochloride (AAPH), which generates alkylperoxyl radicals directly by temperature-dependent unimolecular decomposition within the aqueous phase (Rice-Evans et al. 1996). The peroxyl radicals are rapidly decomposed to alkoxyl radicals (Krainev et al. 1996). In another experiment, we used 1,1-diphenyl-2-picrylhydrazyl (DPPH), a stable, lipidsoluble free radical that exhibits a strong absorption at $516 \mathrm{~nm}$ that is reduced when DPPH reacts with a free radical scavenger (Blois 1958). Finally, using a xanthine oxidase system as a source of superoxide anions and hydroxyl radicals, the scavenging effect of $\mathrm{T}_{3}$ in aqueous solution was investigated by electron paramagnetic resonance (EPR) spectroscopic detection.

\section{Materials and Methods}

\section{Materials}

Thyroid hormones and their analogues, BHT, 2-thiobarbituric acid, trichloroacetic acid, 1,1,3,3tetramethoxypropane, DPPH and probucol were purchased from Sigma (La Verpillère, France); AAPH was from Interchim (Montluçon, France). Superoxide dismutase (SOD) (EC 1·15.1.1), mannitol, xanthine and xanthine oxidase (EC 1.1.3.22) were purchased from Sigma. 5,5-Dimethyl-1-pyrroline $N$-oxide (DMPO) was also purchased at Sigma, and was purified through double distillation and stored under nitrogen at $-70{ }^{\circ} \mathrm{C}$ before use.

\section{AAPH-induced LDL oxidation experiments}

LDL preparation Human plasma was taken into citratephosphate-dextran from healthy volunteers selected by the Blood Transfusion Center of Burgundy, France. The plasma was supplemented with $1 \mathrm{~g} / 1$ EDTA- $\mathrm{Na}_{2}$. LDLs (density $1.019-1.063 \mathrm{~g} / \mathrm{m}$ ) were immediately isolated by density-gradient ultracentrifugation at $4{ }^{\circ} \mathrm{C}$, as previously described (Chomard et al. 1998). Fresh LDLs were kept under argon and in darkness at $4{ }^{\circ} \mathrm{C}$ for up to 15 days. Before use, the LDL-containing fraction was dialyzed in the darkness for $24 \mathrm{~h}$ at $4{ }^{\circ} \mathrm{C}$ against $0.02 \mathrm{M}$ phosphate buffer, $\mathrm{pH} 7 \cdot 4$, containing $0 \cdot 15 \mathrm{M} \mathrm{NaCl}$,
$0.01 \%$ EDTA and 1\% chloramphenicol. The buffer was first made oxygen-free by passage through a Millipore filter, followed by purging with nitrogen for $30 \mathrm{~min}$.

Compound preparations Thyroid hormones and their analogues were dissolved in $300 \mu \mathrm{l} 11 \mathrm{M} \mathrm{NH}_{4} \mathrm{OH}$ and $300 \mu \mathrm{l}$ ethanol, which were quickly made up to $10 \mathrm{ml}$ with extra-pure water. BHT was dissolved first in $300 \mu \mathrm{l}$ ethanol, then in $300 \mu \mathrm{l} 11 \mathrm{M} \mathrm{NH}_{4} \mathrm{OH}$, and the mixture was made up to $10 \mathrm{ml}$ with ethanol. The $1 \mathrm{mM}$ solutions obtained $(\mathrm{pH} 9 \cdot 2)$ were kept for up to 5 days at $4{ }^{\circ} \mathrm{C}$ before being further dissolved $1 / 10$ in water as required for the different tests.

\section{LDL oxidation and conjugated diene measurement} The protein concentration of dialyzed LDL was measured by the method of Lowry modified by Markwell et al. (1978). Dialyzed LDLs were diluted in 0.02 M phosphate buffer, $\mathrm{pH} 7 \cdot 4$, without EDTA, in order to obtain $0.5 \mathrm{~g}$ LDL-protein per liter. Then $860 \mu \mathrm{l}$ EDTA-free buffer, $20 \mu \mathrm{l} 75 \mathrm{mM}$ AAPH, $20 \mu \mathrm{l}$ diluted compound and $100 \mu \mathrm{l}$ diluted LDL were successively added to quartz cuvettes. A cuvette with AAPH alone was used as a control for the absorbance variation of AAPH, a cuvette with LDL alone was used as a control for LDL particle integrity and buffer purity, and a cuvette with LDL and AAPH was used as oxidation control (no compound). Conjugated diene production kinetics were determined by monitoring the change in absorbance at $234 \mathrm{~nm}$ and $37^{\circ} \mathrm{C}$ with a Uvikon 930 spectrophotometer (Kontron, Milan, Italy) equipped with an automated sampler, allowing for 12 samples to be measured simultaneously. Absorbance was measured against the buffer and recorded every $5 \mathrm{~min}$ for $500 \mathrm{~min}$. Final concentrations in the incubation mixture were $50 \mathrm{mg} \mathrm{LDL}-$ protein/1, 1.5 mM AAPH and $2 \mu \mathrm{M}$ studied compounds, except for $\mathrm{T}_{3}$, which was tested at different concentrations $(0 \cdot 25-4 \cdot 00 \mu \mathrm{M})$. The final $\mathrm{pH}$ of the incubation mixture was $7 \cdot 4$.

The experiments were performed using freshly dialyzed LDL. Each LDL oxidation test systematically consisted of one cuvette with AAPH alone, one cuvette with LDL alone, one cuvette with LDL and AAPH (called 'AAPH'), and additional cuvettes with LDL, AAPH and one of the studied compounds (called 'compound').

The absorbances of each cuvette were corrected by subtracting the corresponding initial absorbance and then the absorbance variation of AAPH alone was also subtracted, except for LDL alone. Corrected data were used to plot the diene absorbance against time and to calculate the changes in absorbance/min as a function of time - that is, the oxidation velocities. Three parameters of LDL oxidation were considered (Gieseg \& Esterbauer 1994): the duration of the lag phase $\left(\mathrm{T}_{\mathrm{lag}}\right.$; determined graphically by the time intercept of the tangents to the slow and rapid increase in the kinetic profile), the maximum velocity of diene production $\left(\mathrm{V}_{\max }\right)$, and the maximum amount of 
generated dienes $\left(\mathrm{D}_{\max }\right)$. The conversion of absorbances into concentrations was based on a diene molar absorptivity of $29500 \mathrm{~mol}^{-1}$ liter $\mathrm{cm}^{-1}$.

Because LDLs isolated from different donors exhibit different oxidizability characteristics, the data of oxidation parameters in the presence of the compounds were corrected with the data in the absence of the compounds. The corrected parameters were indicated by the symbol $\Delta$ $\left(\Delta \mathrm{T}_{\text {lag }}, \Delta \mathrm{V}_{\max }, \ldots\right)$. Consequently, the data of oxidation parameters in the presence of AAPH without compounds were set at 0 , and the more the oxidation parameter value of a compound was different from 0 , the more this compound had an effect on the parameter concerned.

LDL oxidation and thiobarbituric acid-reactive substances measurement Mixtures similar to those prepared for measurement of conjugated diene were placed in darkness at $37^{\circ} \mathrm{C}$. At 1, 2, 4, 6 and $8 \mathrm{~h}, 500 \mu \mathrm{l}$ aliquots were taken and placed in Pyrex centrifuge tubes with screw caps. LDL oxidation was stopped by adding $50 \mu \mathrm{l}$ EDTA-BHT (11 and $2 \cdot 2 \mathrm{mM}$ respectively) and by storing the closed tubes at $4{ }^{\circ} \mathrm{C}$. One milliliter freshly prepared thiobarbituric acid-reactive substances (TBARS) reagent was added, and the closed tubes were mixed and heated at $100{ }^{\circ} \mathrm{C}$ for $15 \mathrm{~min}$. The TBARS reagent was $100 \mathrm{ml}$ of trichloracetic, thiobarbituric and chlorhydric acids (13.6: $0 \cdot 36: 2 \cdot 4 \%, \mathrm{w} / \mathrm{v}$ ) which were mixed and purged under nitrogen for $30 \mathrm{~min}$. Then the tubes were cooled and centrifuged at 2500 r.p.m. for $15 \mathrm{~min}$, and the absorbance of the supernatant was measured at $532 \mathrm{~nm}$ against a control tube without LDL oxidation mixture. Quantification of TBARS was performed by comparison with a standard curve of malondialdehyde equivalents generated by acid-catalyzed hydrolysis of 1,1,3,3-tetramethoxypropane. This curve was obtained in the same conditions as above, using the EDTA-free buffer in place of the LDL oxidation mixture, and ranged from 0 to $8 \mu \mathrm{M}$.

\section{DPPH experiments}

The experiments were performed in absolute ethanol. A $200 \mu \mathrm{M}$ DPPH solution was kept for one night at $4{ }^{\circ} \mathrm{C}$ until dilution to $50 \mu \mathrm{M}$ as required. Probucol, a potent DPPH radical scavenger (Hiramatsu et al. 1994), was used as a control for $100 \%$ scavenging. Probucol, BHT, thyroid compounds and their analogues were dissolved in $100 \mu \mathrm{l}$ $11 \mathrm{M} \mathrm{NH}_{4} \mathrm{OH}$ and quickly made up to $2 \mathrm{ml}$ with absolute ethanol to obtain a $5 \mathrm{mM}$ concentration. To plastic microcuvettes, we successively added $1000 \mu \mathrm{l}$ DPPH dilution and $10 \mu \mathrm{l}$ compound solutions or ethanol (DPPH alone). The absorbance of each mixture was simultaneously measured, every $1 \mathrm{~min}$ for $30 \mathrm{~min}$ at $20^{\circ} \mathrm{C}$, at $516 \mathrm{~nm}$ against ethanol, using the previously described Uvikon 930 spectrophotometer.

The absorbance kinetics showed that $30 \mathrm{~min}$ was the incubation time necessary to reach a stable absorbance for
DPPH alone and for DPPH in the presence of probucol. Therefore, the percentage of radical scavenging against probucol was calculated with absorbances at $30 \mathrm{~min}$ as $100 \times(\mathrm{AD}-\mathrm{AC}) /(\mathrm{AD}-\mathrm{AP})$, where $\mathrm{AD}$ was the $\mathrm{ab}-$ sorbance of DPPH alone, and AC and AP the absorbances in the presence of the compounds and probucol respectively.

\section{Hydroxyl and superoxide anion radical scavenging experiments}

Free radical generation was characterized by EPR spin trapping techniques using the spin trap DMPO. EPR spectra were recorded in a flat-type quartz cell at $37^{\circ} \mathrm{C}$ with a Bruker ESP 300-E X-band spectrometer using a TM110 cavity. The following parameters allowed optimal detection of the signals: modulation frequency, $100 \mathrm{kHz}$; modulation amplitude, $0.8 \mathrm{G}$; microwave power, $20 \mathrm{~mW}$; time constant, $0 \cdot 16 \mathrm{~s}$; scan rate, $1 \cdot 19 \mathrm{G} / \mathrm{s}$. Relative radical concentrations (in arbitrary units, AU) were determined by the measurement of the intensity of the two central lines, on spectra recorded with identical spectrometer settings.

Free radical generation was performed in $50 \mathrm{mM}$ phosphate buffer adjusted to $\mathrm{pH} 7 \cdot 4$. Hydroxyl radical was generated by a xanthine-xanthine oxidase system $(25 \mu \mathrm{M}-2.5 \mathrm{mIU} / \mathrm{ml})$ with addition of Fe/EDTA $(5 / 10 \mu \mathrm{M})$ in the presence of the spin trap DMPO $(5 \mathrm{mM})$. The superoxide anion generating system was also xanthine-xanthine oxidase $(500 \mu \mathrm{M}-50 \mathrm{mIU} / \mathrm{ml})$, but in the presence of catalase $(500 \mathrm{IU} / \mathrm{ml})$ and deferoxamine $(1 \mathrm{mM})$, to avoid the conversion of superoxide anion to hydroxyl radical through spontaneous dismutation and Fenton reaction. The DMPO was used at the concentration of $50 \mathrm{mM}$. $\mathrm{T}_{3}$ was first dissolved in $\mathrm{NH}_{4} \mathrm{OH}$, without ethanol, diluted in phosphate buffer, and added to the medium before the xanthine, which starts the enzymatic reaction. Comparisons were made with blanks obtained in identical $\mathrm{pH}$ conditions.

Initiation of the spectra acquisition began $75 \mathrm{~s}$ (hydroxyl) and $60 \mathrm{~s}$ (superoxide) after initiation of the reaction. EPR spectra of the spin-adducts DMPO-OH and DMPO-OOH, corresponding respectively to the adducts of the hydroxyl radical and the superoxide anion radical with DMPO, were recorded. The height of the signal was evaluated and the $\mathrm{IC}_{50}$, corresponding to the substance concentration inducing a signal height reduction of $50 \%$, was determined for each free radical generating system.

\section{Statistics}

Results are presented as means \pm s.E.M. The levels of significance chosen were $P<0 \cdot 05\left(^{*}\right)$ and $P<0 \cdot 01\left(^{* *}\right)$. Statistical analyses were performed by analysis of variance (ANOVA) using the Systat program (Deltasoft, Meylan, France). The post-hoc two-tailed Dunnett test was used to 

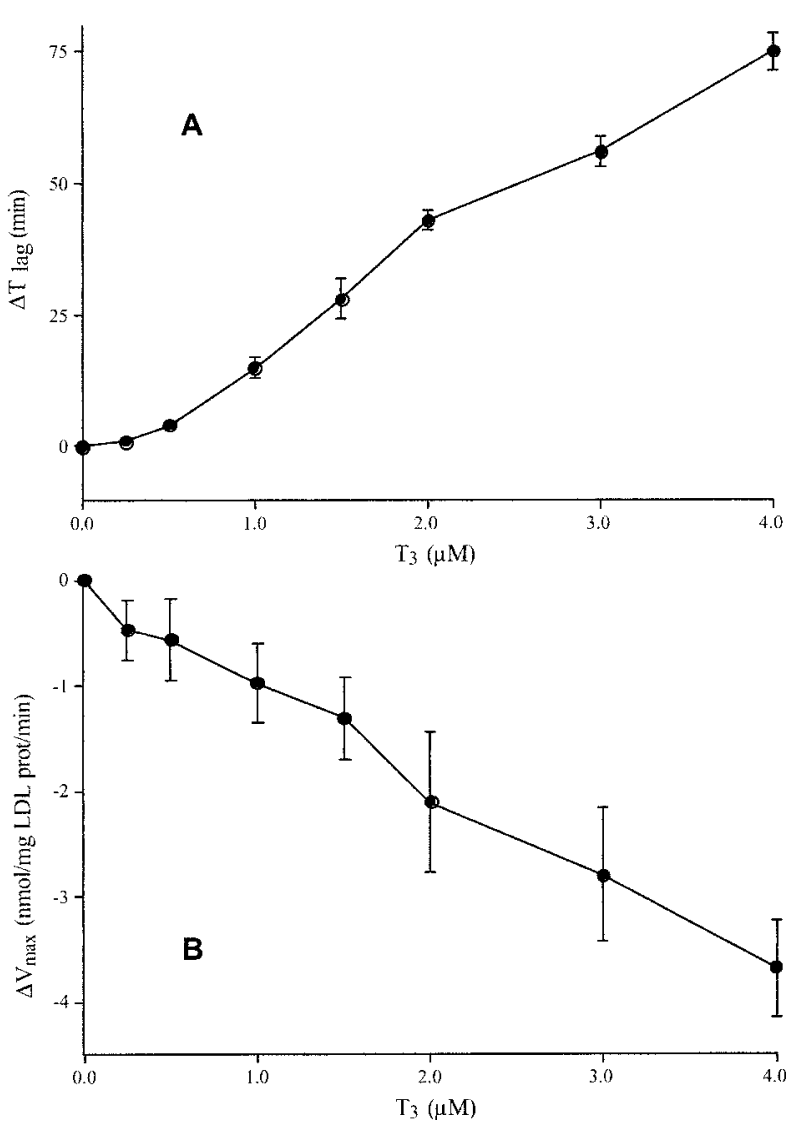

Figure 1 Duration of lag phase $\left(\mathrm{T}_{\text {lag }}\right)(\mathrm{A})$ and maximum velocity of diene production $\left(\mathrm{V}_{\max }\right)(\mathrm{B})$ during oxidation of $\mathrm{LDL}(50 \mathrm{mg}$ protein/l) induced by AAPH $(1.5 \mathrm{mM})$ in the presence of different concentrations of $T_{3}$. Each point is the mean \pm S.E.M. of five experiments expressed in variations $(\Delta)$ against $\mathrm{AAPH}$ without $\mathrm{T}_{3}$.

assess significant differences in parameters between each studied compound and corresponding control. The post-hoc two-tailed Tukey test was then used to determine if there were any differences among active compounds.

\section{Results}

\section{AAPH-induced LDL oxidation experiments}

As $\mathrm{T}_{3}$ concentration increased from $0 \cdot 25$ to $4 \cdot 0 \mu \mathrm{M}, \Delta \mathrm{T}_{\text {lag }}$ increased (Fig. 1A) and $\Delta \mathrm{V}_{\max }$ decreased (Fig. 1B) in an approximately linear manner: $\mathrm{T}_{3}$ had an antioxidant effect that was proportionate to its concentration. At $2 \cdot 0 \mu \mathrm{M} \mathrm{T}$, $\Delta \mathrm{T}_{\text {lag }}$ was increased by about $50 \%$ as compared with AAPH without $T_{3}$. Furthermore, at this $T_{3}$ concentration, a slight break appeared in the slope of each relationship. This concentration was then used for the study of all the other compounds.

Examples of diene absorbance kinetics measured during one LDL oxidation experiment in the presence of the different compounds $(2 \mu \mathrm{M})$ are given in Fig. 2. In the absence of AAPH, LDLs were slightly oxidized by air, whereas in the presence of AAPH, absorbance kinetics revealed the three characteristic phases of LDL oxidation: lag phase, propagation phase and decomposition phase. In the presence of AAPH and MIT, the kinetic was slightly shifted to the left of that obtained with AAPH alone, whereas the kinetics obtained in the presence of $\mathrm{rT}_{3}, \mathrm{~T}_{4}$ and $\mathrm{TA}_{4}$ were slightly shifted to its right. Note the particular aspect of these three kinetics at the beginning of the reaction, making difficult the measurement of $\mathrm{T}_{\text {lag. }}$. In the presence of $\mathrm{T}_{0}, \mathrm{~T}_{3}, \mathrm{TA}_{3}$ and $\mathrm{BHT}$, the kinetics were clearly shifted to the right, indicating the antioxidant efficiency of these compounds, particularly $\mathrm{T}_{0}$. Finally, taking into account all the kinetics except that of LDL alone, maximum absorbance variations, which correspond to the $\mathrm{D}_{\max }$ parameter, were approximately similar.

Values of the LDL oxidation parameters in the presence of the compounds, as expressed in variations against AAPH without compound, are presented in Table 1. MIT, $\mathrm{T}_{4}$ and $\mathrm{TA}_{4}$ did not significantly modify the oxidation parameter values, except for $\mathrm{D}_{\max }$, which was slightly increased. In the same way, $\mathrm{rT}_{3}$ had no effect except on $\mathrm{T}_{\text {lag }}$, which was somewhat increased. In contrast, $\mathrm{T}_{0}, \mathrm{~T}_{3}$ and $\mathrm{TA}_{3}$ had no significant effect on $\mathrm{D}_{\max }$, but clearly increased $\mathrm{T}_{\text {lag }}$ and decreased $\mathrm{V}_{\text {max }}$, whereas BHT was only efficient in increasing $T_{\text {lag. }}$. Using the Tukey test to differentiate among active compounds, $\mathrm{rT}_{3}$ and $\mathrm{T}_{0}$ increased $\mathrm{T}_{\text {lag }}$ less $(P<0 \cdot 01)$ than did $\mathrm{T}_{3}, \mathrm{BHT}$ and $\mathrm{TA}_{3}$, whereas $\mathrm{T}_{3}$ and $\mathrm{TA}_{3}$ decreased $\mathrm{V}_{\max }$ less $(P<0 \cdot 05)$ than $\operatorname{did} \mathrm{T}_{0}$.

Figure 3 summarizes the global antioxidant potency of the compounds - that is, their capacity to increase $T_{\text {lag }}$, decrease $V_{\text {max }}$, or both. Each ellipsoid is the mean \pm s.E.M. of $\mathrm{V}_{\max }$ (vertical diameter) and $\mathrm{T}_{\mathrm{lag}}$ (horizontal diameter), as expressed in variation percentages against AAPH without compound. The point of intersection of 0 values corresponds to AAPH alone; the more the ellipsoids are under or to the right of the AAPH point, the more the corresponding compound has an antioxidant efficiency. This allows clear identification of three groups among the thyronines: $\mathrm{rT}_{3}, \mathrm{~T}_{4}$ and $\mathrm{TA}_{4}$ which had very little, if any, effect; $\mathrm{T}_{3}$ and $\mathrm{TA}_{3}$ which increased $\mathrm{T}_{\mathrm{lag}}$ about $90 \%$ and decreased $\mathrm{V}_{\max }$ about $23 \%$; and $\mathrm{T}_{0}$ which increased $\mathrm{T}_{\text {lag }}$ $67 \%$ and decreased $\mathrm{V}_{\max } 59 \%$. As a comparison, BHT increased $\mathrm{T}_{\text {lag }}$ as $\mathrm{TA}_{3}$ did (92\%), but had no effect on $\mathrm{V}_{\max }$.

Production of TBARS during AAPH-induced LDL oxidation is shown in Fig. 4. When AAPH was omitted, TBARS increased slowly, reaching a value of about $8 \mathrm{nmol} / \mathrm{mg}$ LDL protein after $8 \mathrm{~h}$ of incubation. In the presence of AAPH, TBARS increased considerably after $1 \mathrm{~h}$, reaching a maximum of about $30 \mathrm{nmol} / \mathrm{mg} \mathrm{LDL}$ protein at $4 \mathrm{~h}$, then decreasing slowly. In the presence of the compounds, amounts of TBARS at $1 \mathrm{~h}$ were similar to those obtained with AAPH alone, whereas they were 


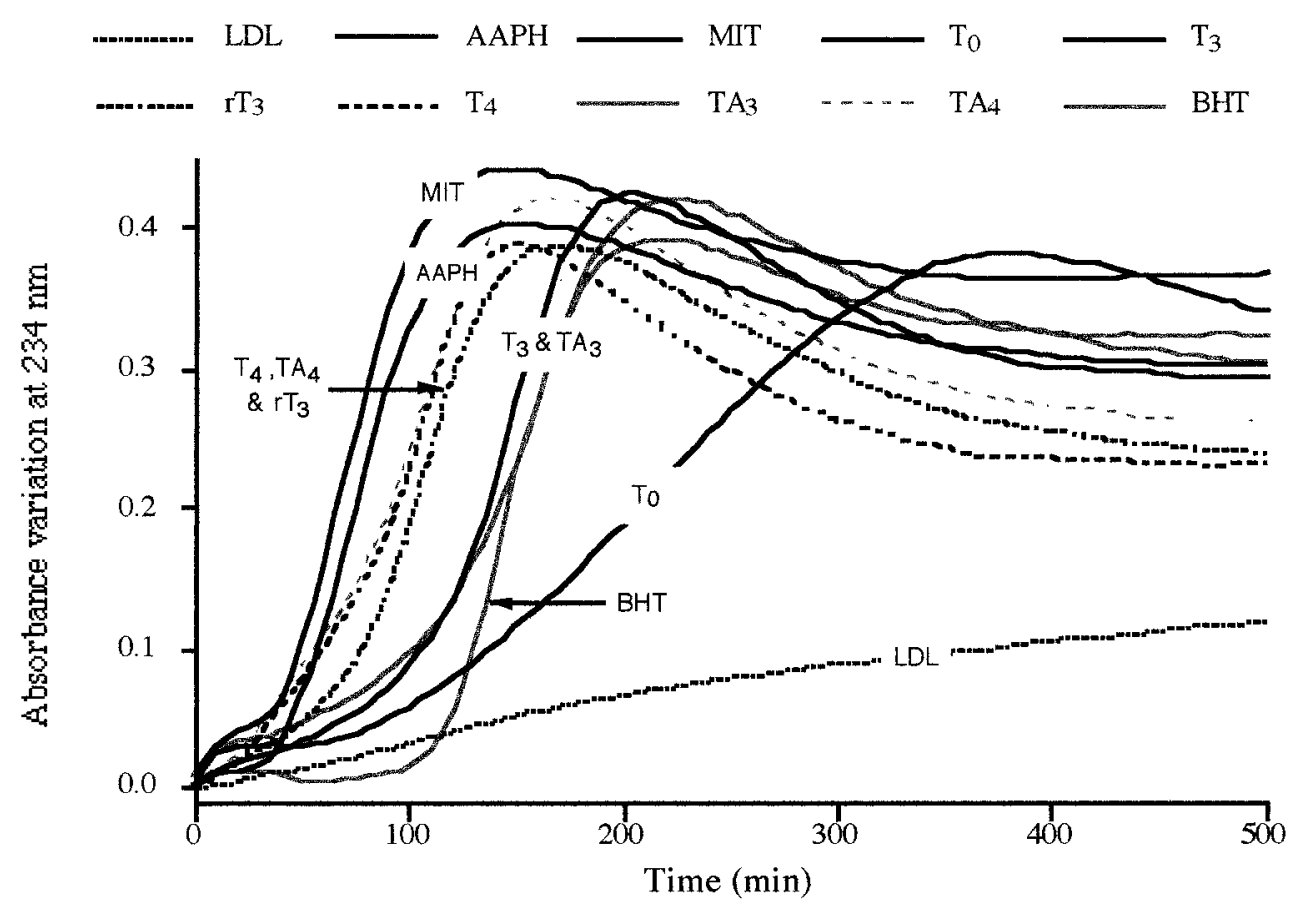

Figure 2 Example of conjugated diene absorbance kinetic measured during one oxidation experiment of $\mathrm{LDL}(50 \mathrm{mg}$ protein/l) in air (LDL, no added AAPH) or induced by AAPH $(1.5 \mathrm{mM})$ in the absence (AAPH) or presence of BHT and different thyroid analogues $(2 \mu \mathrm{M})$.

slightly increased after $4 \mathrm{~h}$. However amounts of TBARS were significantly decreased at $2 \mathrm{~h}$ with $\mathrm{T}_{0}, \mathrm{~T}_{3}, \mathrm{TA}_{3}$ and $\mathrm{BHT}$, and at $4 \mathrm{~h}$ with $\mathrm{T}_{0}$. Note that TBARS production kinetics were somewhat similar to those obtained during measurements of conjugated diene (Fig. 2), that of MIT

Table 1 Duration of lag phase $\left(\mathrm{T}_{\mathrm{lag}}\right)$, maximum velocity of diene production $\left(\mathrm{V}_{\max }\right)$ and maximum amount of generated dienes $\left(\mathrm{D}_{\max }\right)$ during oxidation of LDL (50 mg protein/l) induced by AAPH $(1.5 \mu \mathrm{M})$ in the presence of BHT and different thyroid compounds $(2 \mu \mathrm{M})$. Values are means \pm S.E.M. of seven experiments

\begin{tabular}{|c|c|c|c|}
\hline & $\begin{array}{l}\mathbf{T}_{\mathbf{l a g}} \\
(\mathrm{min})\end{array}$ & $\begin{array}{l}\mathbf{V}_{\max } \\
(\mathrm{nmol} / \mathrm{mg} \\
\text { LDL-protein } \\
\text { per min) }\end{array}$ & $\begin{array}{l}\mathbf{D}_{\max } \\
\text { (nmol/mg } \\
\text { LDL-protein) }\end{array}$ \\
\hline $\mathrm{AAPH}$ & $63 \pm 4 \cdot 0$ & $6 \cdot 3 \pm 0 \cdot 8$ & $379 \pm 30$ \\
\hline$\Delta \mathrm{MIT}$ & $-8 \pm 2$ & $+0 \cdot 2 \pm 0 \cdot 2$ & $+42 \pm 10^{*}$ \\
\hline$\Delta \mathrm{T}_{0}$ & $+38 \pm 7^{* *}$ & $-3 \cdot 6 \pm 0.4^{* *}$ & $+16 \pm 12$ \\
\hline$\Delta \mathrm{T}_{3}$ & $+51 \pm 5^{* *}$ & $-1 \cdot 5 \pm 0.5^{*}$ & $+19 \pm 9$ \\
\hline$\Delta \mathrm{rT}_{3}$ & $+22 \pm 4^{*}$ & $-0.6 \pm 0.4$ & $+25 \pm 10$ \\
\hline$\Delta \mathrm{T}_{4}$ & $+11 \pm 5$ & $-0.7 \pm 0.6$ & $+35 \pm 9^{*}$ \\
\hline$\Delta \mathrm{TA}_{3}$ & $+55 \pm 5^{* *}$ & $-1 \cdot 8 \pm 0 \cdot 6^{*}$ & $+30 \pm 13$ \\
\hline$\Delta \mathrm{TA}_{4}$ & $+15 \pm 3$ & $-1 \cdot 2 \pm 0 \cdot 3$ & $+51 \pm 10^{* *}$ \\
\hline$\Delta \mathrm{BHT}$ & $+52 \pm 9^{* *}$ & $+0 \cdot 2 \pm 0.3$ & $+15 \pm 9$ \\
\hline
\end{tabular}

$\Delta$, Variations against AAPH without compound (AAPH). ${ }^{*} P<0 \cdot 05,{ }^{* *} P<0 \cdot 01$ compared with AAPH (Dunnett test). being shifted to the left of that obtained with AAPH alone and those of the others being more or less shifted to its right, reaching their maximum at about $6 \mathrm{~h}$.

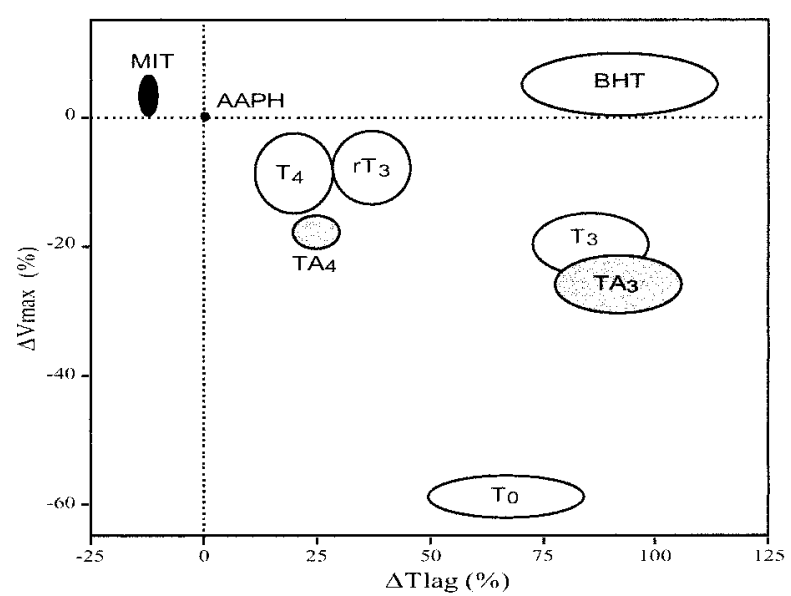

Figure 3 Maximum velocity of diene production $\left(\mathrm{V}_{\max }\right)$ as a function of the duration of the lag phase $\left(T_{1 a g}\right)$ during oxidation of $\mathrm{LDL}(50 \mathrm{mg}$ protein/l) induced by AAPH $(1.5 \mathrm{mM})$ in the presence of $2 \mu \mathrm{M}$ MIT (dark ellipsoid), different thyronines (white ellipsoids), acetic derivatives (deep-gray ellipsoids) and BHT (light-gray ellipsoid). The center of each ellipsoid is the mean of seven experiments, expressed in variation ( $\Delta$ in \%) against AAPH without compound; vertical and horizontal diameters of each ellipsoid are S.E.M. of $\Delta \mathrm{V}_{\max }$ and $\Delta \mathrm{T}_{\text {lag }}$ respectively. 


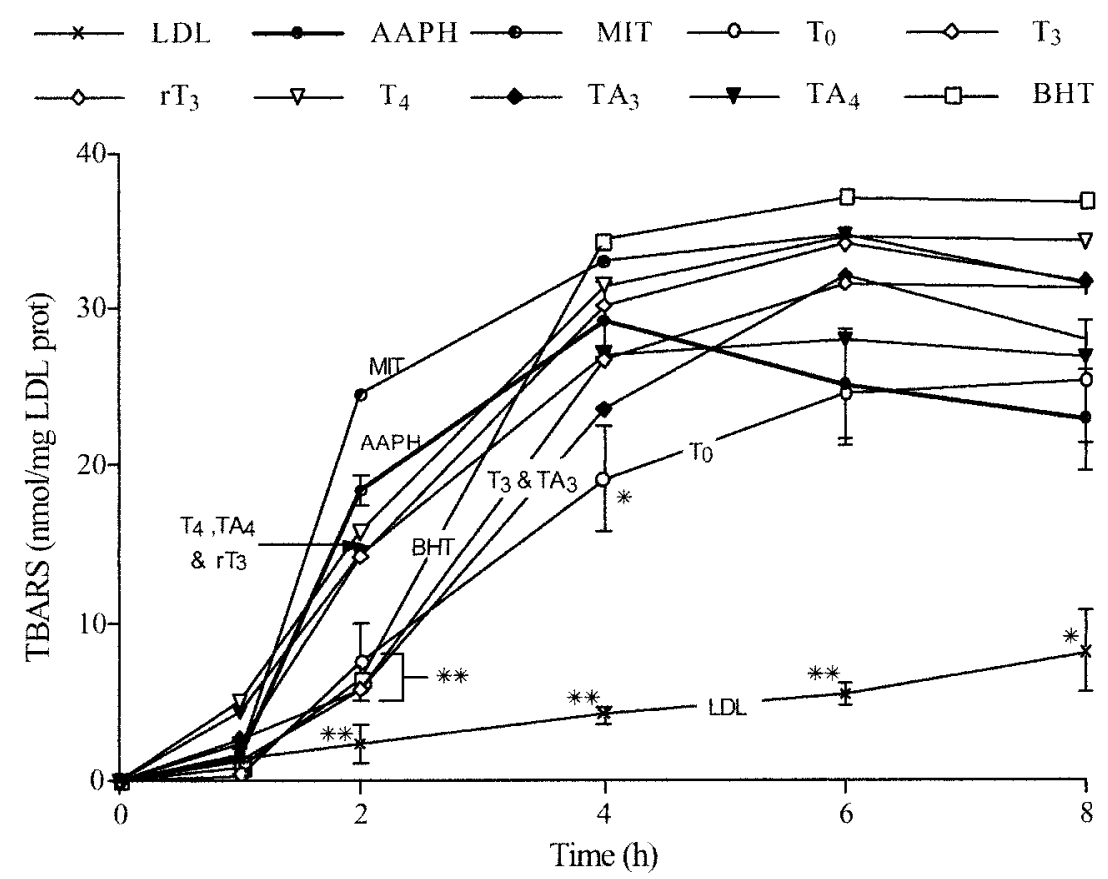

Figure 4 Production of TBARS during oxidation of LDL $(50 \mathrm{mg}$ protein/l) in air (LDL, no added AAPH) or induced by AAPH $(1.5 \mathrm{mM})$ in the absence $(\mathrm{AAPH})$ or presence of BHT and different thyroid analogues $(2 \mu \mathrm{M}) .{ }^{*} P<0.05$ and ${ }^{* *} P<0 \cdot 01$ compared with AAPH without thyroid analogue at the same time (Dunnett test).

\section{DPPH experiments}

All the compounds, except MIT, revealed DPPH radical scavenging capacities (Fig. 5). However, radical scavenging activity of the thyroid compounds was lower than that of BHT (34\%). Among them, $\mathrm{T}_{0}, \mathrm{~T}_{3}$ and $\mathrm{TA}_{3}$ had the weakest activity (about $8 \%) ; \mathrm{T}_{4}(14 \%)$ had greater activity than $\mathrm{T}_{0}$ and $\mathrm{T}_{3}\left(P<0 \cdot 05\right.$; Tukey), and $\mathrm{rT}_{3}$ and $\mathrm{TA}_{4}$ had the most marked activity (about 21\%), which differed from that of $\mathrm{T}_{0}, \mathrm{~T}_{3}$ and $\mathrm{TA}_{3}(P<0 \cdot 01$; Tukey).

\section{Hydroxyl and superoxide anion radical scavenging experiments}

The spectra corresponding to DMPO-OOH and DMPO-OH are shown in Fig. 6. The $\mathrm{IC}_{50}$ values for the superoxide (DMPO-OOH) and hydroxyl (DMPO-OH) radical adducts are indicated in Fig. 7. Figures 6A and 7A show the diminution in the peak height of the DMPO-OOH signal for $\mathrm{T}_{3}$ over a range of concentrations. $\mathrm{T}_{3}$ was effective as a superoxide scavenger at a concentration less than $2.5 \mathrm{mM}$, but no total inhibition of the signal was seen at greater concentrations, because of the insolubility of the compound. The $\mathrm{IC}_{50}$ of $\mathrm{T}_{3}$ for superoxide anion was found to be $2 \cdot 2 \mathrm{mM}$; as a comparison, the water-soluble analogue of vitamin E, Trolox, showed an $\mathrm{IC}_{50}$ of $1 \mathrm{mM}$ (Walker et al. 1998). $\mathrm{T}_{3}$ also scavenged hydroxyl radicals at concentrations less than $0.4 \mathrm{mM}$, as seen in Figs $6 \mathrm{~B}$ and $7 \mathrm{~B}$. The $\mathrm{IC}_{50}$ of $\mathrm{T}_{3}$ was around $0.22 \mathrm{mM}$. As a comparison, the $\mathrm{IC}_{50}$ of mannitol for scavenging the hydroxyl radical is $8 \mathrm{mM}$.

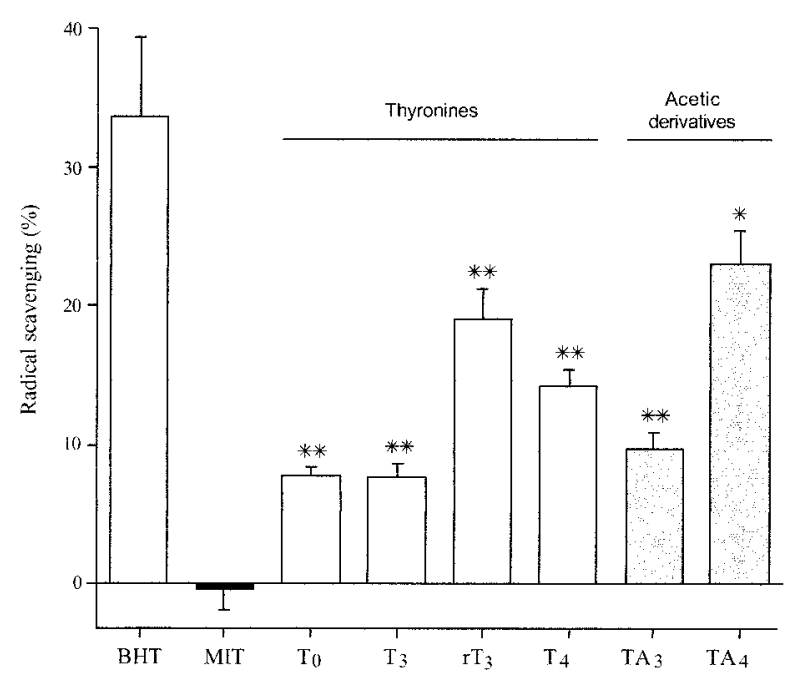

Figure 5 Percentage of radical scavenging against probucol (100\%) of BHT and different thyroid analogues. Radical scavenging was obtained by measuring the decrease in absorbance of DPPH $(50 \mu \mathrm{M})$ after $30 \mathrm{~min}$ in the presence of the compounds $(50 \mu \mathrm{M})$. Each value is the mean \pm S.E.M. of 11 experiments. All the values are different from $0(P<0 \cdot 01)$, except that of MIT. ${ }^{*} P<0 \cdot 05$ and ${ }^{* \star P} P<0 \cdot 01$ compared with BHT for active thyroid analogues (Dunnett test). 

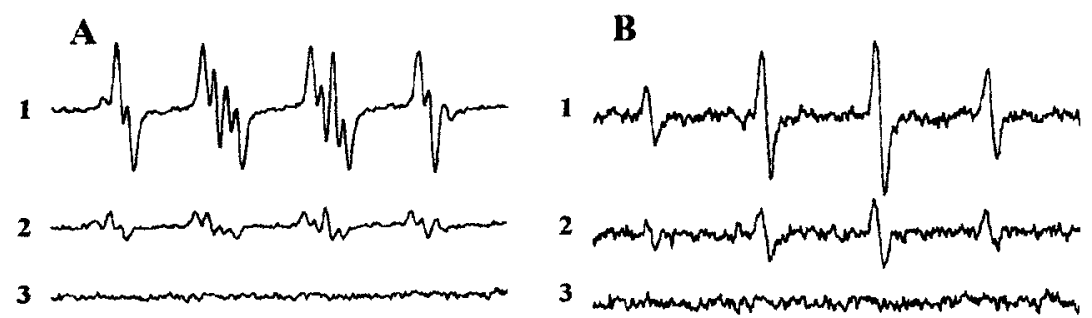

Figure 6 EPR spectra of the radical adduct of superoxide (A) and hydroxyl (B) with DMPO. (A) EPR signal corresponding to DMPO-OOH (aN=14.3 G, aH $\beta=11.3 \mathrm{G}, \mathrm{aH} \gamma=1.4 \mathrm{G}$, $g=2.006)$ obtained with xanthine $(500 \mu \mathrm{M})$, xanthine oxidase $(50 \mathrm{mlU} / \mathrm{ml})$, catalase $(500$ $\mathrm{IU} / \mathrm{ml})$, deferoxamine $(1 \mathrm{mM})$ and DMPO $(50 \mathrm{mM})$. $1=$ blank; $2=$ plus $\mathrm{T}_{3}(2.5 \mathrm{mM})$; $3=$ same as 1, but without xanthine. (B) EPR signal corresponding to DMPO-OH $(\mathrm{aN}=\mathrm{aH}=14.9 \mathrm{G}, \mathrm{g}=2 \cdot 006)$ obtained with xanthine $(25 \mu \mathrm{M})$, xanthine oxidase $(2 \cdot 5$ $\mathrm{mIU} / \mathrm{ml}), \mathrm{Fe} / \operatorname{EDTA}(5 / 10 \mu \mathrm{M})$ and DMPO $(5 \mathrm{mM}) .1=$ blank; $2=$ plus $\mathrm{T}_{3}(200 \mu \mathrm{M}) ; 3=$ same as 1 , but without xanthine.

\section{Discussion}

It has been reported that thyroid hormones and structural analogues limited in vitro LDL oxidation induced by $\mathrm{Cu}^{2+}$ (Hanna et al. 1993, Chomard et al. 1998) or human endothelial cells (Hanna et al. 1995). Here, we show that it was also true using the free radical generator, $\mathrm{AAPH}$, and that thyroid compounds revealed free radical scavenging properties.

During $\mathrm{Cu}^{2+}$-induced LDL oxidation, binding of $\mathrm{Cu}^{2+}$ to apolipoprotein B100 of LDL is necessary for the generation of the initiating radical (Kuzuya et al. 1992, Gieseg \& Esterbauer 1994, Wagner \& Heinecke 1997). Thus antioxidants that inhibited $\mathrm{Cu}^{2+}$-induced LDL oxidation may first act by chelating copper, as reported for caffeic acid (Nardini et al. 1995) or flavonoids (Brown et al. 1998). In the present study, thyroid compounds decreased the production of conjugated diene and TBARS during LDL oxidation induced by AAPH. This clearly indicates that these compounds exert an antioxidant effect on LDL oxidation independently of metal-ion chelation. However, it may be suspected that thyroid compounds also disturb $\mathrm{Cu}^{2+}$ binding on apolipoprotein B100. Indeed, during $\mathrm{Cu}^{2+}$-induced LDL oxidation (Chomard et al. 1998), i) $\mathrm{TA}_{3}$ had a much greater antioxidant effect than $\mathrm{T}_{3}$, whereas it was similar in the present study, ii) $\mathrm{TA}_{4}$ strongly decreased $\mathrm{V}_{\max }$ by about $80 \%$, more than $\mathrm{T}_{3}(45 \%)$, whereas it only decreased it by $9 \%$ here, and iii) $\mathrm{rT}_{3}$ had an antioxidant effect similar to that of $\mathrm{T}_{3}$, whereas it had practically no effect here.

Among the oxidation parameters, $\mathrm{T}_{\text {lag }}$ represents the lag-phase during which endogenous lipophilic antioxidants such as $\alpha$-tocopherol prevent radical chain propagation, whereas $V_{\text {max }}$ is the maximum velocity of the rapid propagation phase occurring when endogenous antioxidants are consumed. $\mathrm{As}_{3}, \mathrm{TA}_{3}$ and $\mathrm{T}_{0}$ increased $\mathrm{T}_{\text {lag }}$, one may think that they act by sparing endogenous lipophilic antioxidants. Although possible, this mechanism does not account for the entire antioxidant effect of the thyroid compounds. Firstly, they also decreased $V_{\max }$, whereas BHT (an $\alpha$-tocopherol-sparing compound) did not. Indeed, it has been reported that BHT at $2 \mu \mathrm{M}$, the same concentration as in the present study, decreased the rate of $\alpha$-tocopherol degradation during AAPH-induced LDL oxidation (Bowry \& Stocker 1993). Secondly, the kinetic profile for the initiation phase in the presence of BHT was clearly horizontal until the propagation phase (Fig. 2), whereas those with $\mathrm{T}_{3}, \mathrm{TA}_{3}$ and $\mathrm{T}_{0}$ rapidly curved, suggesting that the radical chain-breaking capacity of endogenous antioxidants was not highly preserved.

Thus $T_{3}, T_{3}$ and $T_{0}$ should essentially act as free radical scavengers in AAPH-induced LDL oxidation. AAPH resides almost entirely in the aqueous phase and generates, at a constant rate, a continuous flux of free radical $\left(\mathrm{AAPH}^{\bullet}\right)$ which rapidly reacts with dioxygen to give the initiating alkylperoxyl radical (AAPH-OO ${ }^{\bullet}$ ) (Rice-Evans et al. 1996, Thomas et al. 1997). This alkylperoxyl radical must then diffuse into the LDL particle to initiate peroxidation. As active thyroid compounds were able to slow down the initiation phase, and owing to the assumption that they did not essentially spare endogenous antioxidants, one may think that they scavenged the AAPH-derived alkylperoxyl radical directly in the aqueous phase. However, because they particularly decreased $\mathrm{V}_{\max }$ of the propagation phase, they would also be able to scavenge peroxyl radicals within the lipid phase. This is compatible with the relatively amphiphilic character of thyroid compounds in our conditions of low molar concentrations at $\mathrm{pH} 7 \cdot 4$ and $37^{\circ} \mathrm{C}$.

Our data obtained in EPR experiments confirmed that $\mathrm{T}_{3}$ was able to scavenge free radicals generated in an aqueous buffer. It was able to scavenge superoxide radical at a concentration range similar to that described for Trolox, the water-soluble analogue of vitamin E. However, the $\mathrm{IC}_{50}$ of $\mathrm{T}_{3}$ for scavenging $\mathrm{O}_{2}^{\bullet-}(2 \cdot 2 \mathrm{mM})$ was 

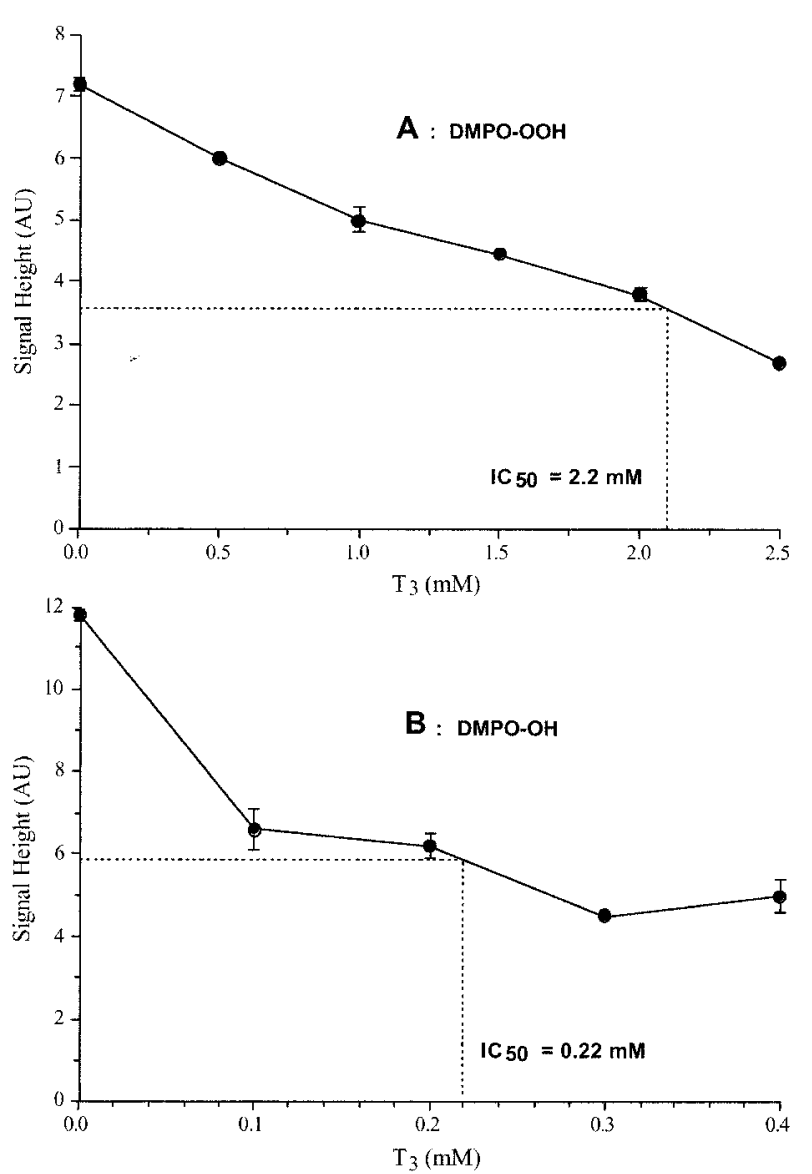

Figure 7 Inhibition of spin adducts signal height by increasing $T_{3}$ concentrations. (A) Inhibition of superoxide anion adducts (DMPO-OOH). (B) Inhibition of hydroxyl radical adducts (DMPO-OH). Each point represents the mean of four individual measurements.

almost twice that of Trolox. The potency of the hormone for scavenging the very active hydroxyl radical was high. In fact, the $\mathrm{IC}_{50}$ was $0.22 \mathrm{mM}$, which was a concentration 36-fold lower than that observed for mannitol. As a comparison, in a different buffer, the $\mathrm{IC}_{50}$ of Trolox for scavenging ${ }^{\bullet} \mathrm{OH}$ was about $1 \mathrm{mM}$ (Walker et al. 1998). These results suggest that $T_{3}$ may be a very potent scavenger against the oxygen-derived free radicals occurring during physiopathological processes.

In contrast, during the DPPH experiments, $\mathrm{T}_{3}$ revealed relatively weak scavenging capacity for the low-reactive DPPH radical, with regard to BHT and probucol. Furthermore and surprisingly, $\mathrm{T}_{4}, \mathrm{TA}_{4}$ and $\mathrm{rT}_{3}$ revealed DPPH radical scavenging capacities greater than those of $\mathrm{T}_{0}, \mathrm{~T}_{3}$ and $\mathrm{TA}_{3}$, whereas these last compounds had the greatest antioxidant effect on the AAPH-induced LDL oxidation. It is obvious that the number of iodines on the phenolic ring (in $3^{\prime}$ and $5^{\prime}$ ) plays a role in free radical scavenging properties of the thyroid compounds. $\mathrm{T}_{4}, \mathrm{TA}_{4}$ and $\mathrm{rT}_{3}$, which are $3^{\prime}, 5^{\prime}$-di-iodosubstituted, had similar scavenging properties in either DPPH or AAPH experiments; this was also true for $\mathrm{T}_{3}$ and $\mathrm{TA}_{3}$, which are $3^{\prime}$-mono-iodosubstituted. The antioxidant behavior of a compound depends on its different functional groups which affect its lipophilicity and ionization (Macfaul et al. 1996), and consequently it also depends on the reaction solvent. The DPPH experiments were performed in absolute ethanol, whereas the AAPH experiments were performed in aqueous buffer at $\mathrm{pH} 7 \cdot 4$. In this latter medium, $\mathrm{T}_{4}$ and $\mathrm{rT}_{3}$ exist at about $80 \%$ under the phenolate form, whereas $\mathrm{T}_{3}$ and $\mathrm{T}_{0}$ dissociate only $8 \%$ and $0 \cdot 7 \%$ respectively (Jorgensen 1978). Thus, during the AAPH experiments, $3^{\prime}, 5^{\prime}$-di-iodosubstituted compounds may primarily be present in the aqueous medium and may not be able to scavenge peroxyl radicals within the lipid phase. Furthermore, the dissociation into the phenolate form might be responsible for an inefficiency of free radical scavenging.

The 4'-hydroxydiphenylether structure of thyroid compounds was necessary for the free radical scavenging activity. MIT, which possesses the lateral chain and the mono-iodosubstituted phenolic ring of $\mathrm{T}_{3}$, had no effect either on the production of conjugated diene and TBARS during the AAPH-induced LDL oxidation, or on the DPPH free radical. Conversely $\mathrm{T}_{0}$, which possesses the basic structure of thyroid hormones but without iodine, scavenged free radicals in the two systems.

We found that the maximum amounts of conjugated diene $\left(\mathrm{D}_{\max }\right)$ and TBARS after $4 \mathrm{~h}$ incubation were similar, or even increased, in LDLs oxidized by AAPH associated with any of the compounds, as compared with AAPH alone. Thus thyroid compounds slowed down, but did not completely stop LDL oxidation in our experimental conditions. This is not surprising owing to the large AAPH concentration used, which produced $380 \mathrm{nmol} / \mathrm{mg}$ LDL-protein of conjugated diene in about $2 \mathrm{~h}$, whereas the compound concentration was only $40 \mathrm{nmol} / \mathrm{mg}$ LDLprotein. The most likely mechanism for free radical scavenging of thyroid compounds is the formation of an unstable phenoxyl radical that decomposes to stable hydroquinone and (iodo)tyrosine. This oxidative decomposition, known as ether-link cleavage of iodothyronines, may be a minor pathway of catabolism in vivo (Green 1994). Thus a fixed thyroid compound concentration may only scavenge an equal free radical concentration and cannot stop the lipid auto-peroxidation process.

In order to increase measurement sensitivity, AAPHinduced LDL oxidation was performed using a large concentration of pro-oxidant agent on a weak LDL concentration that generated large amounts of conjugated diene and TBARS. As a comparison, LDL TBARS content in normal individuals is about $0 \cdot 2-0 \cdot 8 \mathrm{~mol} / \mathrm{mol}$ LDL (Esterbauer et al. 1992, Kontush et al. 1996), whereas it was about $20 \mathrm{~mol} / \mathrm{mol} \mathrm{LDL}$ after $4 \mathrm{~h}$ of incubation in the present study. Consequently, thyroid compound 
concentration was set to $2 \mu \mathrm{M}$, an $\mathrm{IC}_{50}$ corresponding approximately to the $\mathrm{T}_{3}$ concentration that increased $\mathrm{T}_{\mathrm{lag}}$ by $50 \%$ or decreased $\mathrm{V}_{\max }$ by $50 \%$ (Fig. 3). Thus the thyroid compound concentration used in the AAPH test cannot be compared with physiological serum concentrations of thyroid hormones, which are $50-150 \mathrm{nM}$ for $\mathrm{T}_{4}$, about $2 \mathrm{nM}$ for $\mathrm{T}_{3}, 0.3 \mathrm{nM}$ for $\mathrm{rT}_{3}$, and $0.1 \mathrm{nM}$ for $\mathrm{TA}_{3}$. However, there is no reason to suppose that such a radical scavenging process does not occur in vivo, where LDL oxidation is limited as compared with our experimental conditions. For example, applying conditions near the physiological situation, Hanna et al. (1993) reported finding a $\mathrm{T}_{4} \mathrm{IC}_{50}$ of only $0 \cdot 21 \mu \mathrm{M}$ on air-oxidized LDL. The small fraction of circulating thyroid hormones that is bound to lipoproteins (Benvenga \& Robbins 1993) may well protect the LDL surface from radical attacks, particularly in the arterial intima, where LDL oxidation primarily occurs (Smith et al. 1992, Heinecke 1998, Seiss et al. 1999). In hypothyroidism, the decrease in serum thyroid hormones and in $\mathrm{T}_{3}$ - and $\mathrm{T}_{4}$-LDL binding (Benvenga $\&$ Robbins 1996) might contribute to enhanced LDL peroxidation and thus the atherosclerotic process. Indeed, LDL oxidizability has been reported to be increased in hypothyroid patients (Sundaram et al. 1997, Costantini et al. 1998, Diekmann et al. 1998). However, in such patients, modifications of the LDL fatty acid composition, particularly the lower oleic to linoleic acid ratio (Kleinveld et al. 1993), and increases in circulating total and LDL cholesterol (Martinez Triguero et al. 1998) may also be factors that favor LDL oxidizability.

\section{References}

Benvenga S \& Robbins J 1993 Lipoprotein-thyroid hormone interactions. Trends in Endocrinology and Metabolism 4 194-198.

Benvenga S \& Robbins J 1996 Altered thyroid hormone binding to plasma lipoproteins in hypothyroidism. Thyroid 6 595-600.

Blois MS 1958 Antioxidant determinations by the use of a stable free radical. Nature 181 1199-1200.

Bowry VW \& Stocker R 1993 Tocopherol-mediated peroxidation. The prooxidant effect of vitamin $\mathrm{E}$ on the radical-initiated oxidation of human low-density lipoprotein. Journal of the American Chemical Society 115 6029-6044.

Brown JE, Khodr H, Hider RC \& Rice-Evans CA 1998 Structural dependence of flavonoid interactions with $\mathrm{Cu}^{2+}$ ions: implications for their antioxidant properties. Biochemical Journal 330 1173-1178.

Chomard P, Seguin C, Loireau A, Autissier N \& Artur Y 1998 Effects of iodotyrosines, thyronines, iodothyroacetic acids and thyromimetic analogues on in vitro copper-induced oxidation of low-density lipoproteins. Biochemical Pharmacology 55 1591-1601.

Costantini F, Pierdomenico SD, De Cesare D, De Remigis P, Bucciarelli T, Bittolo Bon G, Cazzolato G, Nubile G, Guagnano MT, Sensi S, Cuccurullo F \& Mezzetti A 1998 Effect of thyroid function on LDL oxidation. Arteriosclerosis, Thrombosis and Vascular Biology 18 732-737.

Diekmann T, Demacker PNM, Kastelein JJP, Stalenhoef AFH \& Wiersinga WM 1998 Increased oxidizability of low-density lipoproteins in hypothyroidism. Journal of Clinical Endocrinology and Metabolism 83 1752-1755.
Esterbauer H, Gebicki J, Puhl H \& Jürgens G 1992 The role of lipid peroxidation and antioxidants in oxidative modification of LDL. Free Radical Biology and Medicine 13 341-390.

Gieseg S \& Esterbauer H 1994 Low density lipoprotein is saturable by pro-oxidant copper. FEBS Letters 343 188-194.

Green WL 1994 Ether-link cleavage of iodothyronines. In Thyroid Hormone Metabolism. Molecular Biology and Alternate Pathways, vol 11, pp 199-221. Eds SY Wu \& TJ Visser. Boca Raton: CRC Press Inc.

Hanna AN, Feller DR, Witiak DT \& Newman HAI 1993 Inhibition of low density lipoprotein oxidation by thyronines and probucol. Biochemical Pharmacology 45 753-762.

Hanna AN, Titterington LC, Lantry LE, Stephens RE \& Newman HAI 1995 Thyronines and probucol inhibition of human capillary endothelial cell-induced low density lipoprotein oxidation. Biochemical Pharmacology 50 1627-1633.

Heinecke JW 1998 Mechanisms of oxidative damage of low density lipoprotein in human atherosclerosis. Atherosclerosis 41 1-15.

Hiramatsu M, Liu J, Edamatsu R, Ohba S, Kadowaki D \& Mori A 1994 Probucol scavenged 1,1-diphenyl-2-picrylhydrazyl radicals and inhibited formation of thiobarbituric acid reactive substances. Free Radical Biology and Medicine 16 201-206.

Jorgensen EC 1978 Thyroid hormones and analogs. I. Synthesis, physical properties and theoretical calculations. In Hormonal Proteins and Peptides, vol VI, pp 57-105. Ed. CH Li. New York: Academic Press.

Kleinveld HA, Naber AHJ, Stalenhoef AFH \& Demacker PNM 1993 Oxidation resistance, oxidation rate, and extent of oxidation of human low-density lipoprotein depend on the ratio of oleic acid content to linoleic acid content: studies in vitamin $\mathrm{E}$ deficient subjects. Free Radical Biology and Medicine 15 273-280.

Kontush A, Hübner C, Finckh B, Kohlschütter A \& Beisiegel U 1996 How different constituents of low density lipoprotein determine its oxidizability by copper: a correlational approach. Free Radical Research 24 135-147.

Krainev AG, Williams TD \& Bigelow DJ 1996 Oxygen centered spin adducts of 5, $5^{\prime}$-dimethyl-1-pyrroline $N$-oxide (DMPO) and 2 H-imidazole 1-oxides. Journal of Magnetism Research Series B 111 272-280.

Kung AWC, Pang RWC, Lauder I, Lam KSL \& Janus ED 1995 Changes in serum lipoprotein(a) and lipids during treatment of hyperthyroidism. Clinical Chemistry 41 226-231.

Kuzuya M, Yamada K, Hayashi T, Funaki C, Naito M, Asai K \& Kuzuya F 1992 Role of lipoprotein-copper complex in copper catalyzed-peroxidation of low-density lipoprotein. Biochimica et Biophysica Acta 1123 334-341.

Macfaul PA, Ingold KU \& Lusztyk J 1996 Kinetic solvent effects on hydrogen atom abstraction from phenol, aniline, and diphenylamine - the importance of hydrogen bonding on their radical-trapping (antioxidant) activities. Journal of Organic Chemistry 61 1316-1321.

Markwell MAK, Haas SM, Buber LL \& Tolbert NE 1978 A modification of the Lowry procedure to simplify protein determination in membrane and lipoprotein samples. Analytical Biochemistry 87 206-210.

Martinez Triguero ML, Hernandez Mijares A, Nguyen TT, Munoz ML, Pena H, Morillas C, Lorente D, Lluch I \& Molina E 1998 Effect of thyroid hormone replacement on lipoprotein(a), lipids, and apolipoproteins in subjects with hypothyroidism. Mayo Clinic Proceedings 73 837-841.

Nardini M, d'Aquino M, Tomassi G, Gentili V, Di Felice M \& Scaccini C 1995 Inhibition of human low-density lipoprotein oxidation by caffeic acid and other hydroxycinnamic acid derivatives. Free Radical Biology and Medicine 19 541-552.

O’Brien T, Katz K, Hodge D, Nguyen T, Kottke BA \& Hay ID 1997 The effect of the treatment of hypothyroidism and hyperthyroidism on plasma lipids and apolipoproteins AI, AII and E. Clinical Endocrinology 46 17-20. 
Rice-Evans CA, Leake D, Bruckdorfer KR \& Diplock AT 1996 Practical approaches to low density lipoprotein oxidation: whys, wherefores and pitfalls. Free Radical Research 25 285-311.

Siess W, Zangl KJ, Essler M, Bauer M, Brandl R, Corrinth C, Bittman R, Tigyi G \& Aepfelbacher M 1999 Lysophosphatidic acid mediates the rapid activation of platelets and endothelial cells by mildly oxidized low density lipoprotein and accumulates in human atherosclerotic lesions. PNAS 96 6931-6936.

Smith CA, Mitchinson MS, Arvora OI \& Halliwell B 1992 Stimulation of lipid peroxidation and hydroxyl radical generation by the contents of human atherosclerotic lesions. Biochemical Journal 286 901-905.

Steinberg D 1997 Low density lipoprotein oxidation and its pathobiological significance. Journal of Biological Chemistry $\mathbf{2 7 2}$ 20963-20966.

Sundaram V, Hanna AN, Koneru L, Newman HAI \& Falko JM 1997 Both hypothyroidism and hyperthyroidism enhance low density lipoprotein oxidation. Journal of Clinical Endocrinology and Metabolism 82 3421-3424

Thomas MJ, Chen QR, Franklin C \& Rudel LL 1997 A comparison of the kinetics of low-density lipoprotein oxidation initiated by copper or by azobis (2-amidinopropane). Free Radical Biology and Medicine 23 927-935.

Wagner P \& Heinecke JW 1997 Copper ions promote peroxidation of low density lipoprotein lipid by binding to histidine residues of apolipoprotein B100, but they are reduced at other sites on LDL. Arteriosclerosis, Thrombosis and Vascular Biology 17 3338-3346.

Walker MK, Vergely C, Lecour S, Abadie C, Maupoil V \& Rochette L 1998 Vitamin E analogues reduce the incidence of ventricular fibrillations and scavenge free radicals. Fundamental and Clinical Pharmacology 12 164-172.

Received in final form 20 March 2001

Accepted 20 March 2001 